\title{
MEASUREMENT OF SOIL TENSILE STRENGTH AND FACTORS AFFECTING ITS MEASUREMENTS
}

\author{
Surendra Bahadur Tamrakar ${ }^{\mathrm{i})}$, Toshiyuki Mitachi ${ }^{\text {ii) }}$ and Yasuo Toyosawaiii)
}

\begin{abstract}
This paper describes the tensile strength measured for three kinds of statically compacted unsaturated soils; mixtures of clay $\sim$ silt $\sim$ sand, Narita-sand and Kanto loam. Specimens were directly prepared either under controlled compaction stress or under controlled dry density by statically compacting them within the tensile mold of the apparatus. Image analysis was done to show the normality of tensile force to the tensile failure plane. Tensile strengths $\left(q_{\mathrm{t}}\right)$ were compared with the unconfined compressive strengths $\left(q_{\mathrm{u}}\right)$ for silt $\sim$ sand mixture, clay $\sim$ sand mixture, clay $\sim$ silt mixture and Narita sand, respectively. Increment in tensile strength (also $q_{\mathrm{u}} / q_{\mathrm{t}}$ ratio) with the increase in the percentage and decrease in the size of finer soils could be seen. Effects of number of compaction layers and tensile pulling rates on the $q$ $t$ were also examined. Increase in the tensile strength with the increase in the number of compaction layers was observed; and it was suggested to prepare the unsaturated compacted specimen by 3 to 4 layers compaction. Increase in tensile strength of $0.3 \mathrm{kPa}$ and $0.003 \mathrm{kPa}$ per one cycle of logarithm of tensile pulling rate was observed for clay $\sim$ sand-4 (1:3) and clay $\sim$ sand-5 (3:1) for the pulling rate of 0.01 to $1.0 \mathrm{~mm} / \mathrm{min}$.
\end{abstract}

Key words: compacted soil, rate effect, tensile strength, test equipment (IGC: D6/D9)

\section{INTRODUCTION}

Most of the vertical slopes get failed with the development of tensile crack on the top of the slope. Also, many earth dams, embankments, pavements, etc. where soil layers are compacted, are failed due to the development of tensile cracks. Prediction of probable position and depth of tensile crack is necessary to protect the property and loss of lives of workers at the construction site. In order to explain the position and depth of tensile crack, an accurate measurement of tensile strength of soil is necessary. Very few researches (e.g., Suzuki et al., 1998; Yao et al., 2002; Ono et al., 2003) have been made to measure the tensile strength of soils having lower tensile values. Recently, Nahlawi et al. (2004) and Tamrakar et al. (2005a) have introduced a new tensile strength measuring apparatus which measures the tensile strength directly. One developed by Nahlawi et al. (2004) could be mainly used for compacted clayey and stiff soils only whereas the one developed by Tamrakar et al. (2005a) seems to be easy to use and simple to handle and could be used for both compacted unsaturated and highly saturated soils.

Tamrakar et al. (2005a, b) measured the maximum tensile strength of Kanto loam around $50 \sim 60 \%$ of water content and showed the ratio of $q_{\mathrm{u}} / q_{\mathrm{t}}$ around 12.5 which varied with the water content. They also showed the effect of the amount of finer particles and their size on tensile strength. Possible measurement of tensile strength for saturated NSF clay was also shown. Jung et al. (2001) had conducted tensile tests for dry and wet rock specimens, and mentioned about the strain rate effect. Nahlawi et al. (2004) had mentioned about the change in tensile displacement rate while tensile pulling was done at the constant speed depending upon the stiffness of the test specimen. But the research on the effect of tensile pulling rate on soil has not been carried out yet.

In this paper, tensile apparatus (type-A tensile mold) developed by Tamrakar et al. (2005a) was used and the normality of tensile pulling force in respect with tensile failure surface was shown by carrying out image analysis. Also, the effect of the number of compaction layers and tensile pulling rate on the tensile strength of compacted specimens of clay and clay $\sim$ sand mixtures is explained. In addition, unconfined compression tests were also performed and their values were compared with tensile strength.

\section{TEST EQUIPMENT}

Tensile test apparatus shown in Photo 1 consists of horizontal platform upon which apparatus box having two halves; fixed box and movable box, is placed. Inside this box, two tensile molds are placed. The inner shape of

i) Researcher, Laboratory of soil mechanics, Graduate School of Engineering, Hokkaido University, Japan (tamrakar@eng.hokudai.ac.jp).

i) Professor, Laboratory of soil mechanics, Graduate School of Engineering, Hokkaido University, Japan.

iii) Visiting Prof., Construction Safety Division, Japan National Institute of Occupational Safety and Health, Japan.

The manuscript for this paper was received for review on November 16, 2006; approved on May $29,2007$.

Written discussions on this paper should be submitted before May 1, 2008 to the Japanese Geotechnical Society, 4-38-2, Sengoku, Bunkyo-ku, Tokyo 112-0011, Japan. Upon request the closing date may be extended one month. 
a mold is like " $C$ " structure and it holds the specimen. Two molds are screwed to the apparatus boxes separately. One box of the apparatus is fixed to the horizontal platform while the other box can move freely on the horizontal platform. To reduce the friction, linear sliding rollers are placed between the movable box and platform. Movable box is pulled away in horizontal direction until the soil specimen fails in tension with tensile crack appearing at the middle of the specimen where two halves of the mold is attached. A load cell placed between the movable box and motor axis measures the tensile load. This tensile load divided by the area of the tensile crack perpendicular to horizontal pulling direction gives the tensile stress. The minimum width at the constricted section of the mold is $3 \mathrm{~cm}$ and the depth is $5 \mathrm{~cm}$. The apparatus box along with the mold and platform can be completely separated from the motor for preparing the specimen before the test. Compacted soil specimen is prepared within this mold by direct static compression. Once the specimen is ready within the mold for the test, then it is connected to motor shaft.

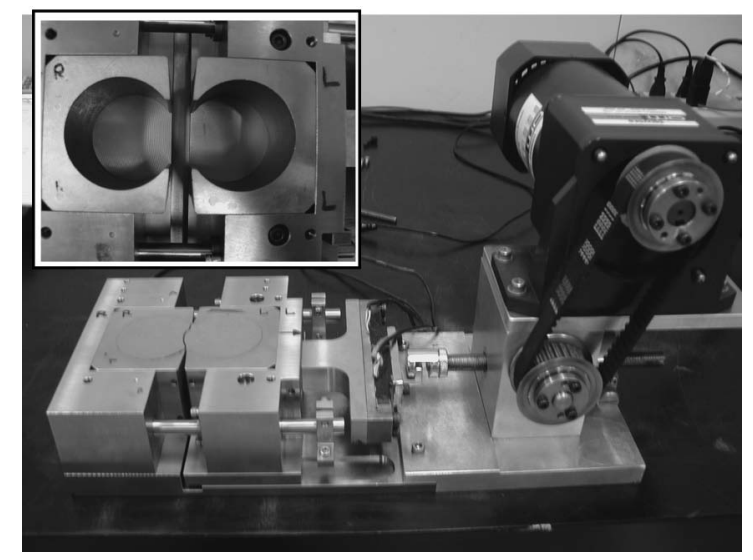

Photo 1. Tensile stress apparatus

\section{SPECIMEN PREPARATION}

Mixtures of NSF-clay $\sim$ CFP-silt and Toyoura-sand (clay $\sim$ silt $\sim$ sand), Narita sand, and Kanto loam were taken as test materials. NSF-clay is commercially available clay which consists of Pyrophylite, CFP-silt (100) is crushed form of Silica sand, and Toyoura sand which was formerly standard sand in Japan is also commercially available. Narita sand and Kanto loam soils were sampled from Toke excavation site of Chiba prefecture, Japan. Grain size distribution curves and index properties for these soils are shown in Table 1 and Fig. 1. Narita sand used here is classified as SF. Now onwards, NSFclay, CFP-silt and Toyoura sand are represented by clay, silt and sand, respectively.

Before preparing the specimens, at first, tensile molds were fixed into the apparatus box and screwing was done between the movable box and apparatus horizontal plate so that movable box would be fixed. To reduce the friction between the specimen and the inner wall of the tensile mold, thin film of grease was applied over its inner surfaces. After the completion of compaction of specimens into the tensile mold, load cell was set up towards the pulling side of mold box. Finally, the screws which were fixed to prevent the movement of movable box of

Table 1. Index properties

\begin{tabular}{l|c|c|c|c|c}
\hline Materials & $\rho_{\mathrm{s}}$ & $w_{\mathrm{L}}$ & $w_{\mathrm{P}}$ & $\rho_{\mathrm{dmax}}$ & $\rho_{\mathrm{dmin}}$ \\
\hline Kanto loam & $\mathrm{g} / \mathrm{cm}^{3}$ & $(\%)$ & $(\%)$ & $\mathrm{g} / \mathrm{cm}^{3}$ & $\mathrm{~g} / \mathrm{cm}^{3}$ \\
\hline NSF-clay & 2.65 & 143.5 & 74.6 & & \\
\hline silt (CFP-100) & 2.66 & & & 1.59 & 1.17 \\
\hline Toyoura sand & 2.64 & & & 1.65 & 1.34 \\
\hline Narita sand & 2.61 & & & & \\
\hline
\end{tabular}

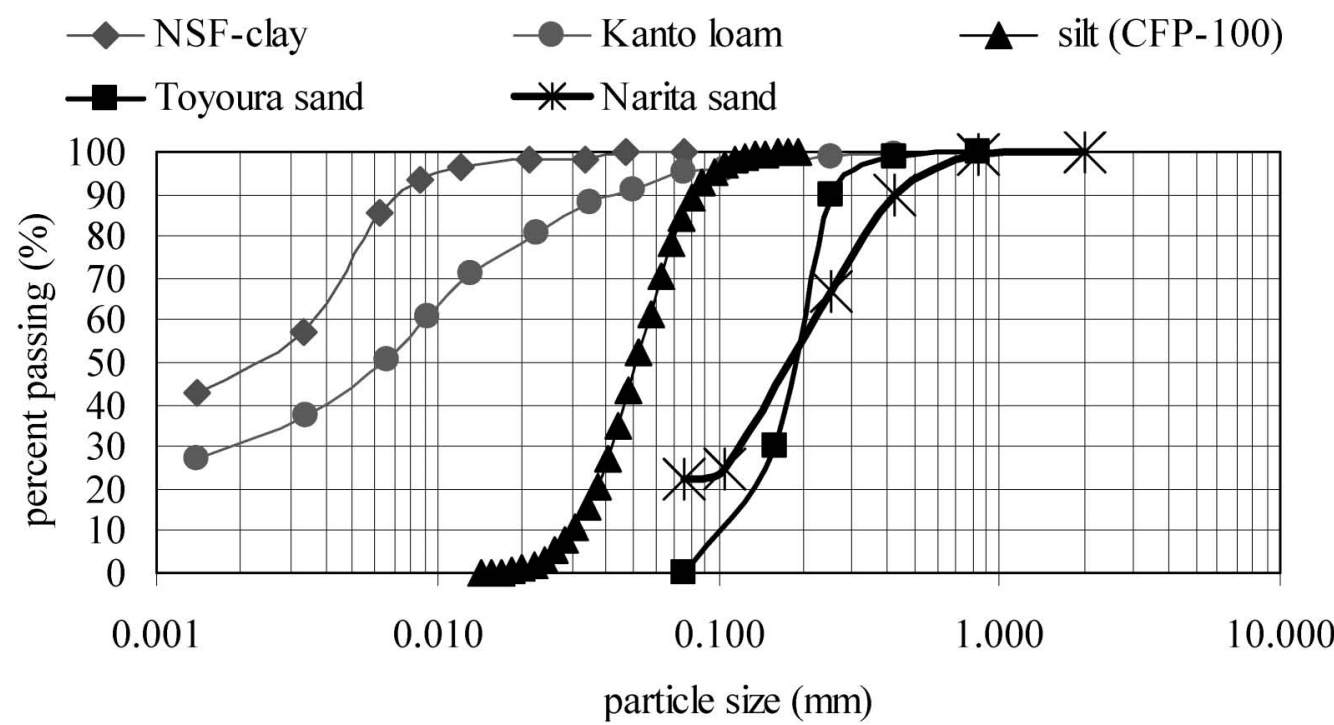

Fig. 1. Grain size distribution curves 
Table 2. Reference tests and $q_{\mathrm{u}} / q_{\mathrm{t}}$ ratio for mixtures

( $w=10 \%, H=5 \mathrm{~cm}$, one-layer compaction, tensile pulling rate $=0.34 \mathrm{~mm} / \mathrm{min}$ )

\begin{tabular}{|c|c|c|c|c|c|c|}
\hline Dry density & NSF-clay & CFP-silt & Toyoura sand & $q_{\mathrm{u}}$ & $q_{\mathrm{t}}$ & $q_{\mathrm{u}} / q_{\mathrm{t}}$ \\
\hline$\left(\mathrm{g} / \mathrm{cm}^{3}\right)$ & $\%$ & $\%$ & $\%$ & $(\mathrm{kPa})$ & $(\mathrm{kPa})$ & \\
\hline \multirow{3}{*}{1.5} & 40 & - & 60 & 55.9 & 6.6 & 8.4 \\
\hline & 50 & - & 50 & 74.4 & 7.8 & 9.5 \\
\hline & 60 & - & 40 & 79.1 & 8.6 & 9.2 \\
\hline \multirow{5}{*}{1.5} & 25 & 75 & - & 64.3 & 6.9 & 9.3 \\
\hline & 40 & 60 & - & 100 & 8.4 & 11.9 \\
\hline & 50 & 50 & - & 97.8 & 8.5 & 11.5 \\
\hline & 60 & 40 & - & 132.2 & 10.3 & 12.9 \\
\hline & 75 & 25 & - & 182.2 & 11.7 & 15.5 \\
\hline \multirow{5}{*}{1.4} & - & 25 & 75 & 6.6 & 1.4 & 4.6 \\
\hline & - & 40 & 60 & 12.9 & 2.2 & 6 \\
\hline & - & 50 & 50 & 16.4 & 2.7 & 6.1 \\
\hline & - & 60 & 40 & 18.7 & 3 & 6.2 \\
\hline & - & 70 & 30 & 26.7 & 3.9 & 6.9 \\
\hline 1.5 & 33.3 & 33.3 & 33.3 & 50.3 & 5.9 & 8.6 \\
\hline
\end{tabular}

the apparatus were un-screwed.

Before making specimens, materials were thoroughly mixed with required distilled water and kept in an air tight container so that water was uniformly distributed throughout the materials. Specimens were prepared either under controlled dry density or under controlled compaction stress conditions. To determine the desired compaction stress as well as dry density (or wet density), stress-density tests were carried out separately in advance. Once the compacting stress or dry density was fixed, then in both conditions, specimens were prepared by directly and statically compressing the prerequisite amount of soil kept within the tensile mold of the apparatus. In case of one layer compaction, whole amount of soil was used at once whereas in multi-layer compaction, the perquisite amount of one layer was divided by the total number of compaction layers and under each compaction layer, such divided amount of soil was added and compressed. Statically loading system with bellofram cylinder was used for compression. Collar was generally placed over the tensile mold to prevent falling out of soil specimens from the tensile mold. Effect of density on the tensile strength was already discussed by Tamrakar et al. (2005a). So, here in this research, only one density was chosen for each group of tests. The samples of clay $\sim$ silt, clay $\sim$ sand and silt $\sim$ sand mixtures shown in Table 2 were made by mixing the materials at different proportions under controlled dry density with one layer compaction. Here the water content $(w)$ for all the specimens was fixed to $10 \%$. Narita sand specimens shown in Table 3 were prepared under controlled compaction stress with one layer compaction. Water content of the test specimen was maintained at around $26 \%$ to approximate the field
Table 3. $q_{\mathrm{u}} / q_{\mathrm{t}}$ for compacted Narita sand

\begin{tabular}{c|c|c|c|c|c}
\hline Compressive stress & $w^{*}$ & $q_{\mathrm{u}}$ & $w^{* *}$ & $q_{\mathrm{t}}^{* * *}$ & $\phi_{\mathrm{u}} / q_{\mathrm{t}}$ \\
\hline $\mathrm{kPa}$ & $\%$ & $\mathrm{kPa}$ & $\%$ & $\mathrm{kPa}$ & \\
\hline 50 & 26.8 & 8 & 26 & 1.4 & 5.7 \\
\hline 100 & 26.2 & 11 & 26 & 1.42 & 7.7 \\
\hline 193 & 26.3 & 15.4 & 25.8 & 1.87 & 9.4 \\
\hline
\end{tabular}

\footnotetext{
* for $q_{\mathrm{u}}$ test

** for $q_{\mathrm{t}}$ test

$* * *$ reference tests
}

condition. Similarly, in Table 4, Kanto loam, clay sand mixtures and Narita sand other than those shown in Tables 2 and 3 are shown. Number of compaction layers and pulling rates were varied according to the type of the tests as shown in Table 4. To compare the tensile strength with unconfined compression strength, specimens for the materials shown in Tables 2 and 3, unconfined compressive tests were carried out. For this, test specimens were prepared either under controlled dry density or under controlled compaction stress with one-layer static compaction by using bellofram cylinder. Other conditions such as dry density and water content were kept at the same condition as those for tensile test specimens shown in Tables 2 and 3.

\section{TESTING CONDITIONS}

Tests in which specimen thickness was maintained at 5 $\mathrm{cm}$ with one-layer compaction and pulled under $0.34 \mathrm{~mm}$ /min tensile pulling rate, were considered as reference 
Table 4. Test materials and test conditions

\begin{tabular}{|c|c|c|c|c|c|c|}
\hline \multirow{3}{*}{ Specimens } & \multirow{3}{*}{$\begin{array}{c}\text { Mixing ratio } \\
\text { by weight }\end{array}$} & \multirow{3}{*}{$\begin{array}{l}w \\
\%\end{array}$} & \multicolumn{2}{|c|}{ Controlled } & \multirow[b]{2}{*}{$\rho_{\mathrm{d}}{ }^{(* *)}$} & \multirow{3}{*}{ Conditions } \\
\hline & & & dry density $\left(\rho_{\mathrm{d}}\right)$ & Compressive stress & & \\
\hline & & & $\mathrm{g} / \mathrm{cm}^{3}$ & $\mathrm{kPa}$ & $\mathrm{g} / \mathrm{cm}^{3}$ & \\
\hline Kanto loam & & 85.0 & & 200 & 0.58 & No. of layers ${ }^{1,(*)}$ \\
\hline clay $\sim$ sand- 1 & $3: 1$ & 10.3 & 1.5 & & & No. of layers ${ }^{1,(*)}$ \\
\hline clay $\sim$ sand- 2 & $1: 3$ & 8.2 & & 200 & 1.48 & No. of layers ${ }^{2,(*)}$ \\
\hline clay $\sim$ sand-3 & $3: 1$ & 7.0 & & 200 & 1.26 & No. of layers ${ }^{2,(*)}$ \\
\hline Narita sand-1 & & 28.3 & & 50 & 1.19 & No. of layers ${ }^{2,(*)}$ \\
\hline Narita sand-2 & & 26.0 & & 100 & 1.19 & No. of layers ${ }^{3,(*)}$ \\
\hline Narita sand-3 & & 25.3 & & 193 & 1.28 & No. of layers ${ }^{1,(*)}$ \\
\hline clay $\sim$ sand- 4 & $1: 3$ & 8.2 & & 200 & 1.5 & Pulling rate ${ }^{(\mathrm{a}), 4}$ \\
\hline clay $\sim$ sand -5 & $3: 1$ & 6.2 & & 200 & 1.28 & Pulling rate $\mathrm{ra}^{(\mathrm{a}), 4}$ \\
\hline
\end{tabular}

${ }^{1}$ one, two and four layer-compaction, ${ }^{2}$ one, two, three and four layer-compaction, ${ }^{3}$ one, three and four layer-compaction, ${ }^{4}$ four layer-compaction (a) $0.01,0.14$ and $1.10 \mathrm{~mm} / \mathrm{min},{ }^{(*)} 0.34 \mathrm{~mm} / \mathrm{min},{ }^{(* *)}$ targetted dry density
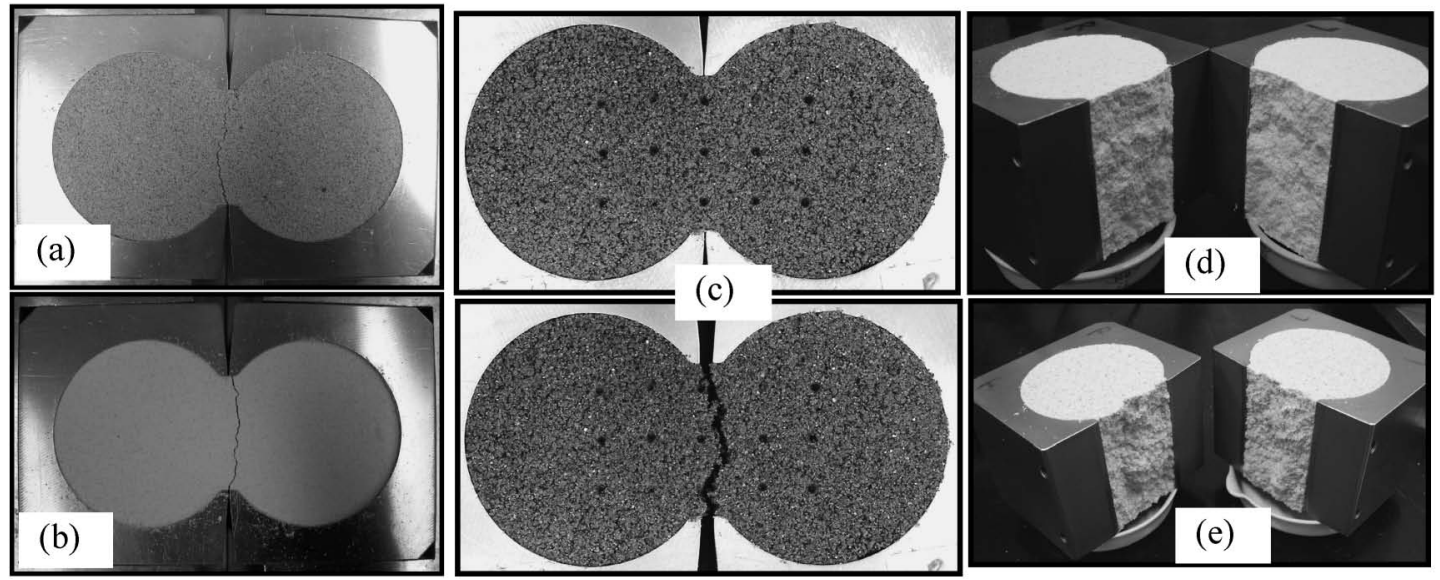

Photo 2. Tensile tests (a) for clay $\sim$ sand-4 (after), (b) for clay $\sim$ sand-5 (after), (c) for Narita sand-1 (before and after), (d) failure plane for clay $\sim$ silt $\sim$ sand $(1: 1: 1)$ and (e) for failure plane clay $\sim \operatorname{sand}(1: 3)$

tests. Test specimens for the materials shown in Tables 2 and 3 were reference tests. To check the effect of number of compaction layers and tensile pulling rates, specimens shown in Table 4 were used. In case of the test where the effect of number of compaction layers was investigated, 5 $\mathrm{cm}$ thick specimens was prepared by compacting the predetermined amount of test materials with 1, 2, 3 and/ or 4 layers (Table 4). Similarly, for the investigation of the effect of tensile pulling rate, $5 \mathrm{~cm}$ thick specimens prepared with four layer compactions were used and they were pulled under $0.01,0.14$ and $1.10 \mathrm{~mm} / \mathrm{min}$ (Table 4). Unconfined compression test specimens, $5 \mathrm{~cm}$ in diameter and $10 \mathrm{~cm}$ in height, were prepared using ordinary splitting mold. Unconfined compression tests were conducted at constant displacement rate of $0.1 \mathrm{~mm} / \mathrm{min}$.

\section{RESULTS AND DISCUSSIONS}

Photos 2(a) and (b) showed the photographs after the tensile failure for clay $\sim$ sand-4 and 5. Almost straight tensile failure crack could be seen. In Photo 2(c), photographs before and after the tensile test for Narita sand (compacted under $50 \mathrm{kPa}$ ) was shown. Here also, almost straight tensile crack along with target points was seen. In Photos 2(d) and (e), failure planes (tensile crack plane) after the tests for clay $\sim$ silt $\sim$ sand $(1: 1: 1)$ and clay $\sim$ sand (1:3) were shown. In both cases, clear and smooth failure surfaces could be seen.

As shown in Photo 2(c), 15 target points were marked on the surface of the specimen ( 3 rows and 5 columns) before the start of the test and photographs were taken before, during and after the test. Relative movements of target points along $X$ and $Y$ directions in respect with the photo before the start of the test were then compared. Here, movement along $X$ direction represents the movement of tensile mold along tensile pulling direction. In contrary, movement along $Y$ direction represents the movement perpendicular to tensile pulling direction. Dis- 

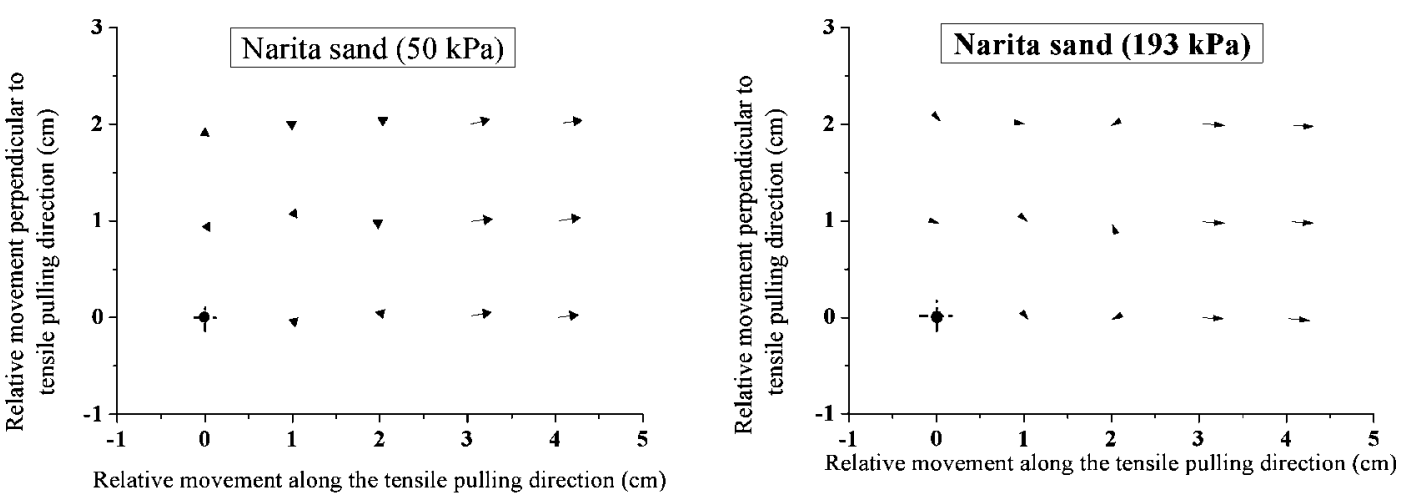

Fig. 2. Movements of points during tensile pulling for Narita sand

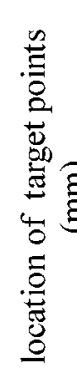

(a) 0

\section{10
0 20
10
0}

relative displacement along $\mathrm{X}$-axis $(\mathrm{mm})$

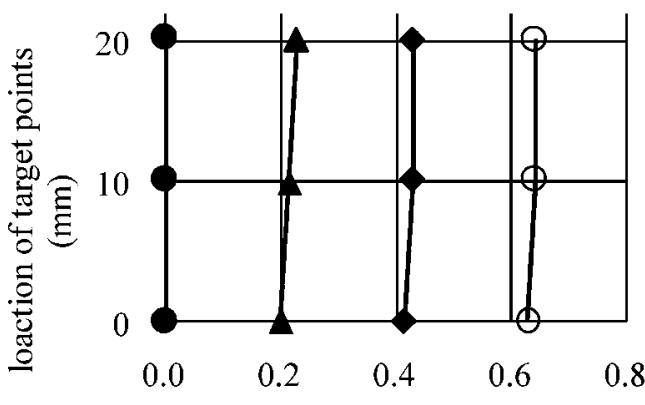

(b) relative displacement along $\mathrm{X}$-axis (mm)

Fig. 3. Displacement of target points during pulling (a) 4th column points and (b) 5th column points

tance between each target points at the beginning is $1 \mathrm{~cm}$. Here, the target point of the first column and first row is considered as reference point. Relative movements of all other target points along and perpendicular to tensile pulling direction are then made with this reference point. In Fig. 2, relative direction and amount of movement after the test for Narita sand specimens compacted under 50 and $193 \mathrm{kPa}$ are shown. Almost no movement was seen for the target points of the first three columns. Target points on the 3rd column lie on the mid portion of the specimen. To locate the target points during image analysis is difficult for these mid points. But targets of 4th and 5th columns showed large movement in both specimens shown in Fig. 2. Relative displacement along $X$-axis observed for 4th and 5th column target points located at $\mathrm{Y}$ $=0,10$ and $20 \mathrm{~mm}$ after the completion of tests were almost straight, showing the movement of movable tensile mold perpendicular to tensile failure plane. In addition, both the columns move similar amount of displacement.

In Fig. 3, relative displacements for target points of 4th and 5th columns are shown with the progress of the tensile pulling for the Narita sand compacted under $193 \mathrm{kPa}$. In case of Narita sand, the maximum tensile stress (tensile strength, $q_{\mathrm{t}}$ ) occurred around $0.1 \mathrm{~mm}$ displacement. As the displacements shown in Fig. 3 started from $0.2 \mathrm{~mm}$, the data observed were after the peak tensile stress. For the reference of tensile pulling positions, tensile stress vs.

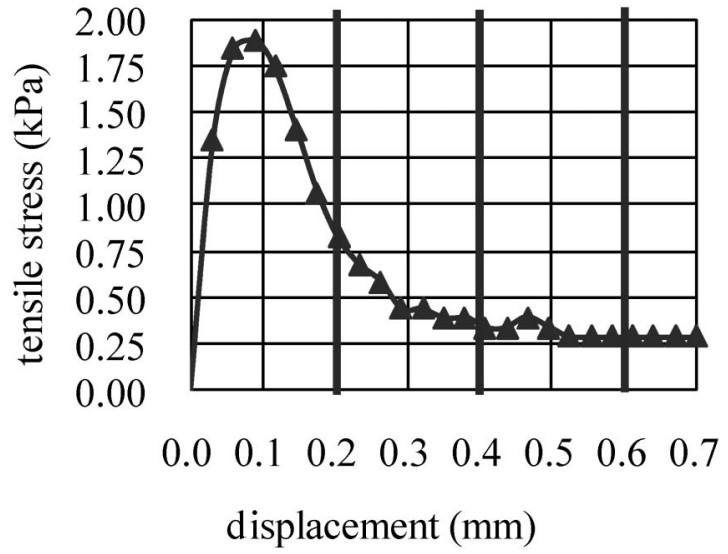

Fig. 4. Tensile stress vs. displacement curve for Narita sand (193 kPa)

displacement curve shown in Fig. 4 could be seen. (In this paper, tensile stress values are shown as positive). Unfortunately, data before the peak strength (tensile strength) could not be obtained. All the lines joining the target points for each step of movement shown in Fig. 3 are not perfectly straight lines. Little deviation in the points might have occurred during positioning the target points for image data. In overall, the directions of movement of target points of 4th and 5th columns are almost perpendicular to tensile plane. Hence, it could be said the tensile force measured with this apparatus acts perpendicularly 

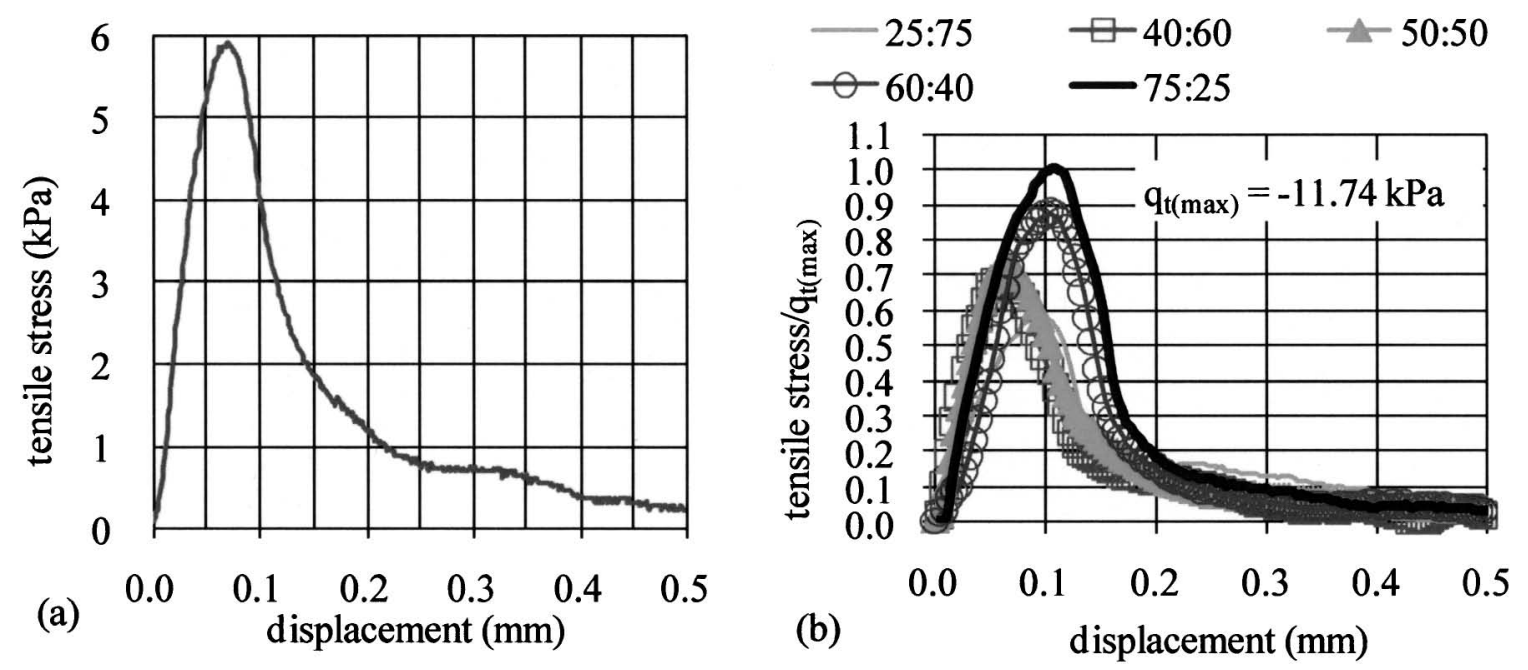

Fig. 5. Tensile stress vs. displacement curves (a) clay $\sim$ silt $\sim$ sand mixture and (b) clay $\sim$ silt mixture
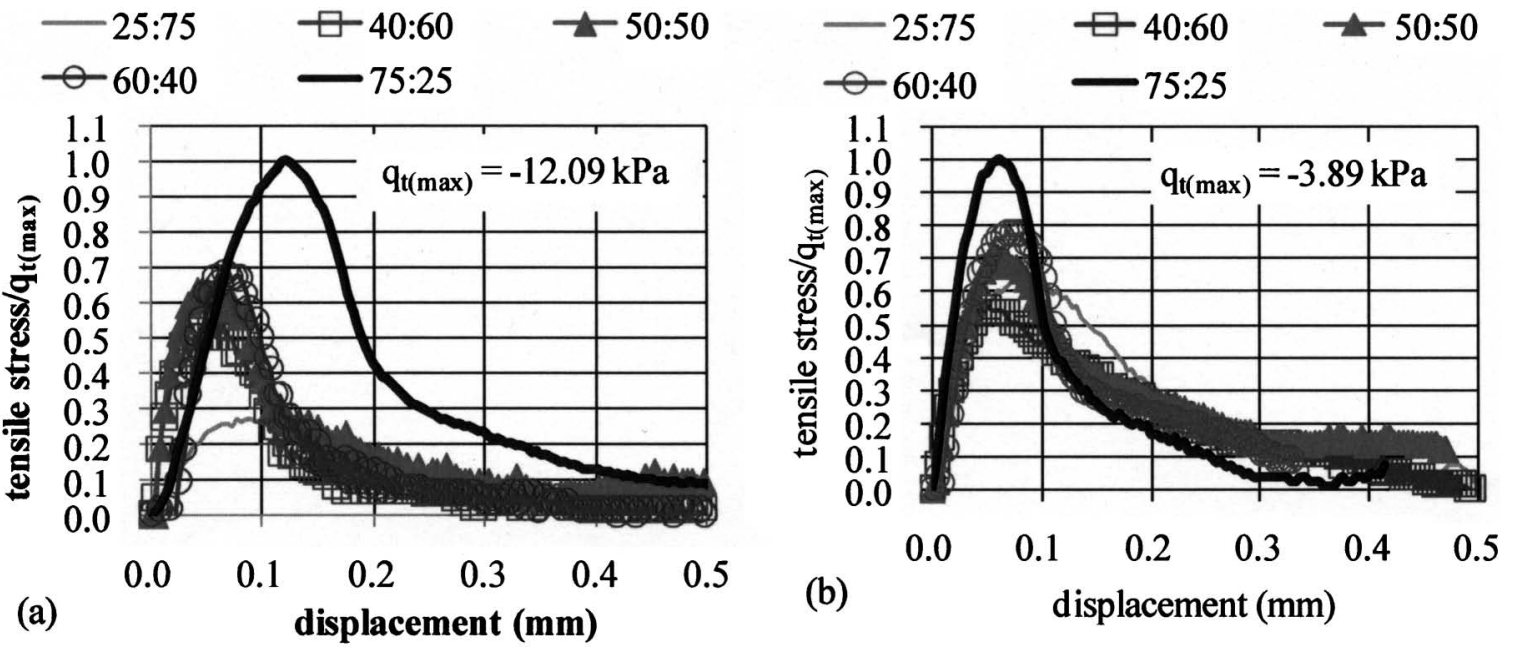

Fig. 6. Tensile stress vs. displacement curves (a) clay $\sim$ sand mixture and (b) silt $\sim$ sand mixture

on the tensile failure plane.

Tensile stress vs. displacement curves obtained for the mixtures of clay $\sim$ silt $\sim$ sand $(1: 1: 1)$ was shown in Fig. 5(a) as a typical example. In Figs. 5(b), 6(a) and 6(b), normalized tensile stress (tensile stress $/ q_{\mathrm{t} \text { (max) }}$ ) vs. displacement curves for different mixtures of clay, silt and sand were shown. Here, $q_{\mathrm{t}(\max )}$ represents the maximum tensile strength in that group of mixture. Normalization of tensile stress with $q_{\mathrm{t}(\max )}$ in each group was done so that the effect of finer particles in each group as well as among the different groups could be compared. In addition, relative tensile strengths could be seen. In each figure clear peaks for tensile stress could be seen. In average, tensile peak values lied within the displacement range of 0.05 to 0.15 $\mathrm{mm}$. By the way, peak values of unconfined compressive strength, $q_{\mathrm{u}}$ lied within the displacement range of 1 to 2 $\mathrm{mm}$ (not shown).

In Tables 2 and 3, $q_{\mathrm{u}}$ and $q_{\mathrm{t}}$ measured for different mixtures and Narita sand were shown. Comparing the ratio of $q_{\mathrm{u}}$ and $q_{\mathrm{t}}$, it was found that the ratio $q_{\mathrm{u}} / q_{\mathrm{t}}$ varied from $4.6 \sim 6.9, \quad 6.5 \sim 10.9, \quad 9.3 \sim 15.5$ and $5.7 \sim 9.4$ for silt $\sim$ sand mixture, clay $\sim$ sand mixture, clay $\sim$ silt mixture and Narita sand, respectively. In Fig. 7, effect of finer particles on tensile strength $\left(q_{\mathrm{t}}\right)$ and strength ratio $\left(q_{\mathrm{u}} / q_{\mathrm{t}}\right)$ are shown. Increment in $q_{\mathrm{t}}$ and strength ratio $\left(q_{\mathrm{u}} /\right.$ $q_{\mathrm{t}}$ ) with the increase in the percentage of fines and decrease in the size of finer soil particles in the soils could be seen. Similar trend of increment in tensile strength with the increase in percentage and size of finer particles had been shown by Tamrakar et al. (2005b). Increment in the tensile strength with the increase in the clay fraction was also shown by Barzegar et al. (1995).

The effect of the number of layers of compaction on tensile strength is shown in Fig. 8. Increment in tensile strength with the increase in the number of compaction layers could be seen except for some specimens like clay $\sim$ sand-1, clay $\sim$ sand-2 and Narita sand- 2 where no increment was observed. But the overall trend of tensile 

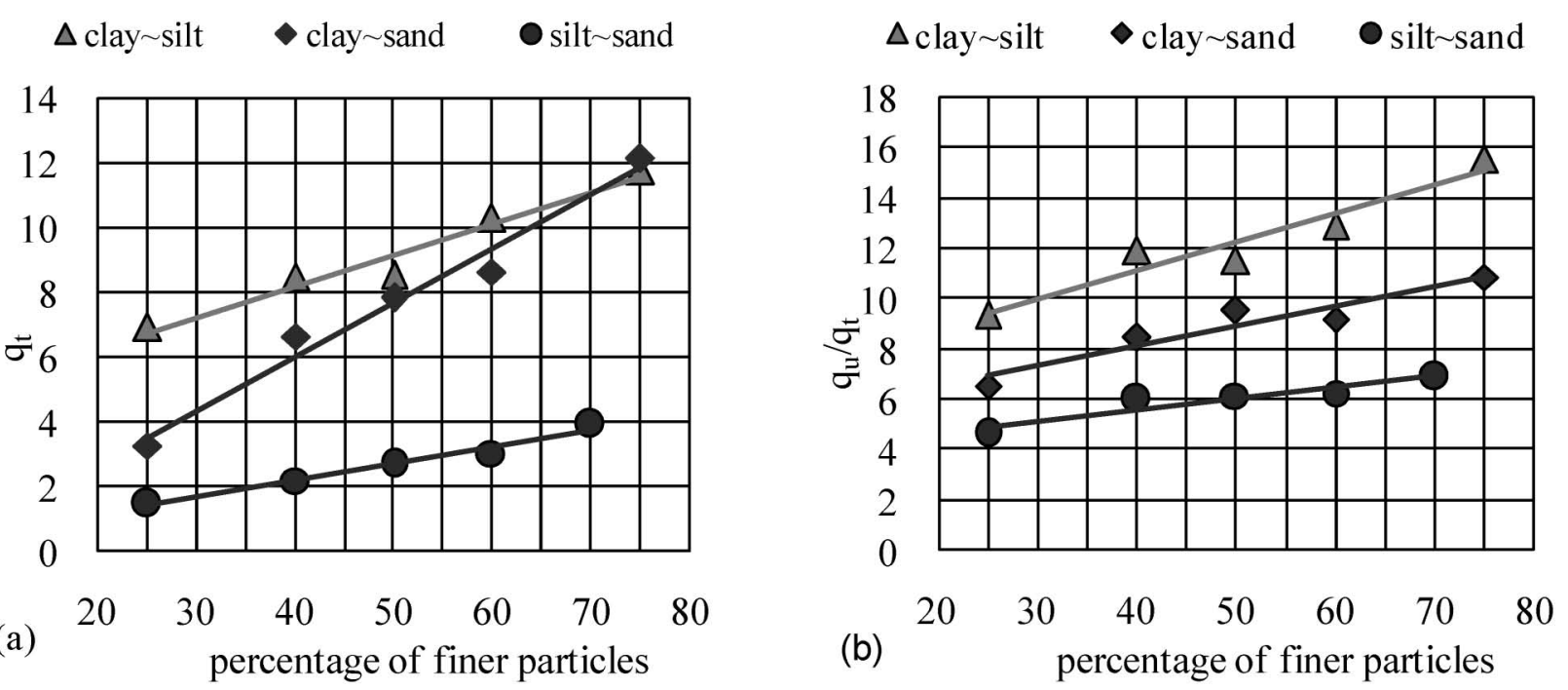

Fig. 7. Effect of percentage of finer particles (a) on tensile strength and (b) strength ratio
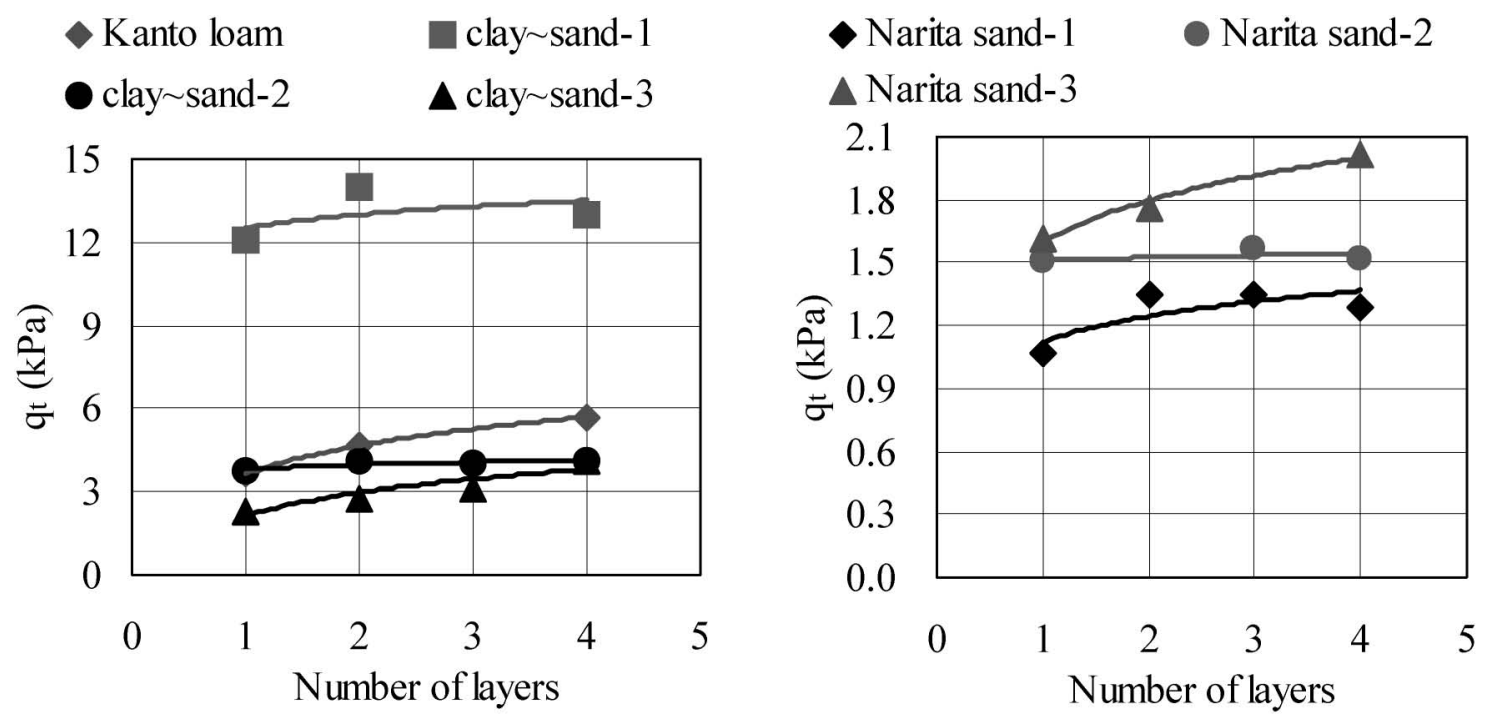

Fig. 8. Effect of number of compaction layers on tensile strength

strength increment with the number of compaction layers was in asymptotic manner. Therefore, in order to reduce the effect of number of compaction layers on tensile strength measurement, it is suggested that the unsaturated compacted specimens be prepared with three or more layers of compaction.

Effect of tensile pulling rate on tensile strength is shown in Fig. 9 for clay $\sim$ sand- 4 and clay $\sim$ sand -5 . Tensile pulling rates varied from $0.01,0.14$ and $1.10 \mathrm{~mm} /$ min. During the test, the whole apparatus along with the test specimen was covered by the plastic box to keep the water content of the specimen constant to prevent any change in suction value. As shown in the figure, it was observed that with the increase in the tensile pulling rate, there was an increase in the tensile strength and the slope of tensile strength versus logarithm of pulling rate is about $0.3 \mathrm{kPa}$ for clay $\sim$ sand-4 (1:3) and $0.003 \mathrm{kPa}$ for clay $\sim$ sand-5 (3:1). Also, from the graph, it could be seen that the increment is higher for the mixture having lower amount of finer particles (clay sand-4 (1:3)) than that having higher amount of finer particles (clay $\sim$ sand -5 (3:1)). Jung et al. (2001) had conducted Brazillian tests for some rocks and showed similar trend of increment in tensile strength with the increase in strain rate.

\section{CONCLUSIONS}

From the tests conducted, the following points can be concluded;

1. Clear and sharp peaks observed in tensile stress vs. displacement plots showed the possibility of measuring tensile strength with this apparatus.

2. Image analysis done for the photographs taken during the test showed that the movable tensile mold of the apparatus moved in perpendicular direction to tensile failure plane or tensile crack. Comparing the 


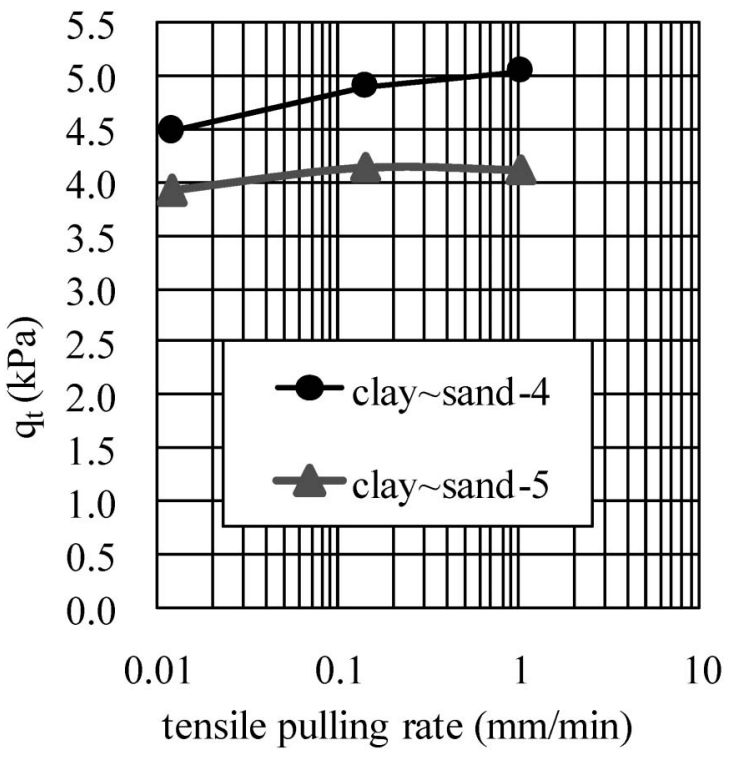

Fig. 9. Effect of tensile pulling rate on tensile strength (under controlled pressure)

movement of target points drawn on the specimen surface, clear movement of one half of the specimen could be observed.

3. Ratio of unconfined compression strength and tensile strength obtained for different unsaturated compacted specimens varied from $4.6 \sim 6.9,6.5 \sim 10.9$, $9.3 \sim 15.5$ and $5.7 \sim 9.4$ for silt $\sim$ sand mixture, clay sand mixture, clay $\sim$ silt mixture and Narita sand, respectively. Increment in tensile strength (also $q_{\mathrm{u}} / q_{\mathrm{t}}$ ratio) with the increase in the percentage and decrease in the size of finer soil particles in the soils could also be observed.

4. Effect of number of layers of compaction (one-layer, two-layer, three-layer and four-layer) on tensile strength was also studied. With the increase in the number of compaction layers, there is increase in tensile strength. Hence it is suggested to prepare the unsaturated compacted specimen by 3 to 4 layers of compaction.
5. Effect of tensile pulling rate on tensile strength was studied and it was found that with the increase in tensile pulling rate, there is increment in tensile strength of $0.3 \mathrm{kPa}$ and $0.003 \mathrm{kPa}$ per one cycle of logarithm of pulling rate for clay $\sim$ sand- 4 and clay $\sim$ sand -5 for the range of 0.01 to $1.0 \mathrm{~mm} / \mathrm{min}$, showing larger increment for soil having lower amount of finer particles that having larger amount.

\section{ACKNOWLEDGEMENTS}

This research is carried out under the Health and Labor Sciences Research Grants of Ministry of Health, Labor and Welfare, Japan.

\section{REFERENCES}

1) Barzegar, A. R., Oades, J. M., Rengasamy, P. and Murray, R. S. (1995): Tensile strength of dry, remoulded soils as affected by properties of the clay fraction, Geoderma, 16, 93-108.

2) Jung, W. J., Ogata, Y., Wada, Y., Seto, M., Katusyama, K. and Ogawa, T. (2001): Effects of water saturation and strain rate on the tensile strength of rocks under dynamic load, Journal of Geotechnical Engineering, JSCE, 673(III-54), 53-59 (in Japanese).

3) Nahlawi, H., Chakrabarti, S. and Kodikara, J. (2004): A direct tensile strength testing method for unsaturated geomaterials, Geotechnical Testing Journal, 27(4), 356-361.

4) Ono, N., Mochizuki, A., Kurosaki, H. and Ueno, K. (2003): Trial tests with compressive and tensile strength measuring apparatus, 58th Annual Meeting of Japanese Society of Civil Engineers, 337-338 (in Japanese).

5) Suzuki, T., Umei, T. and Sunaga, F. (1998): A research on the tensile strength of cement treated soils, 53rd Annual Meeting of Japanese Society of Civil Engineers, JSCE, 600-601 (in Japanese).

6) Tamrakar, S. B., Toyosawa, Y., Mitachi, T. and Itoh, K. (2005a): Tensile strength of compacted and saturated soils using newly developed tensile strength measuring apparatus, Soils and Foundations, 45(6), 103-111.

7) Tamrakar, S. B., Mitachi, T., Toyosawa, Y. and Itoh, K. (2005b): Development of a new soil tensile strength test apparatus, Proc. Geo-Frontiers 2005, Geotechnical Special Publication 138 (CD-ROM) Site Characterization and Modeling, ASCE, Reston, Va.

8) Yao, S., Masui, T. and Ito, A. (2002): The relationship between tensile strength and the state of water in Kaolin clay, 47th Symposium on Geotechnical Symposium, 127-132 (in Japanese). 